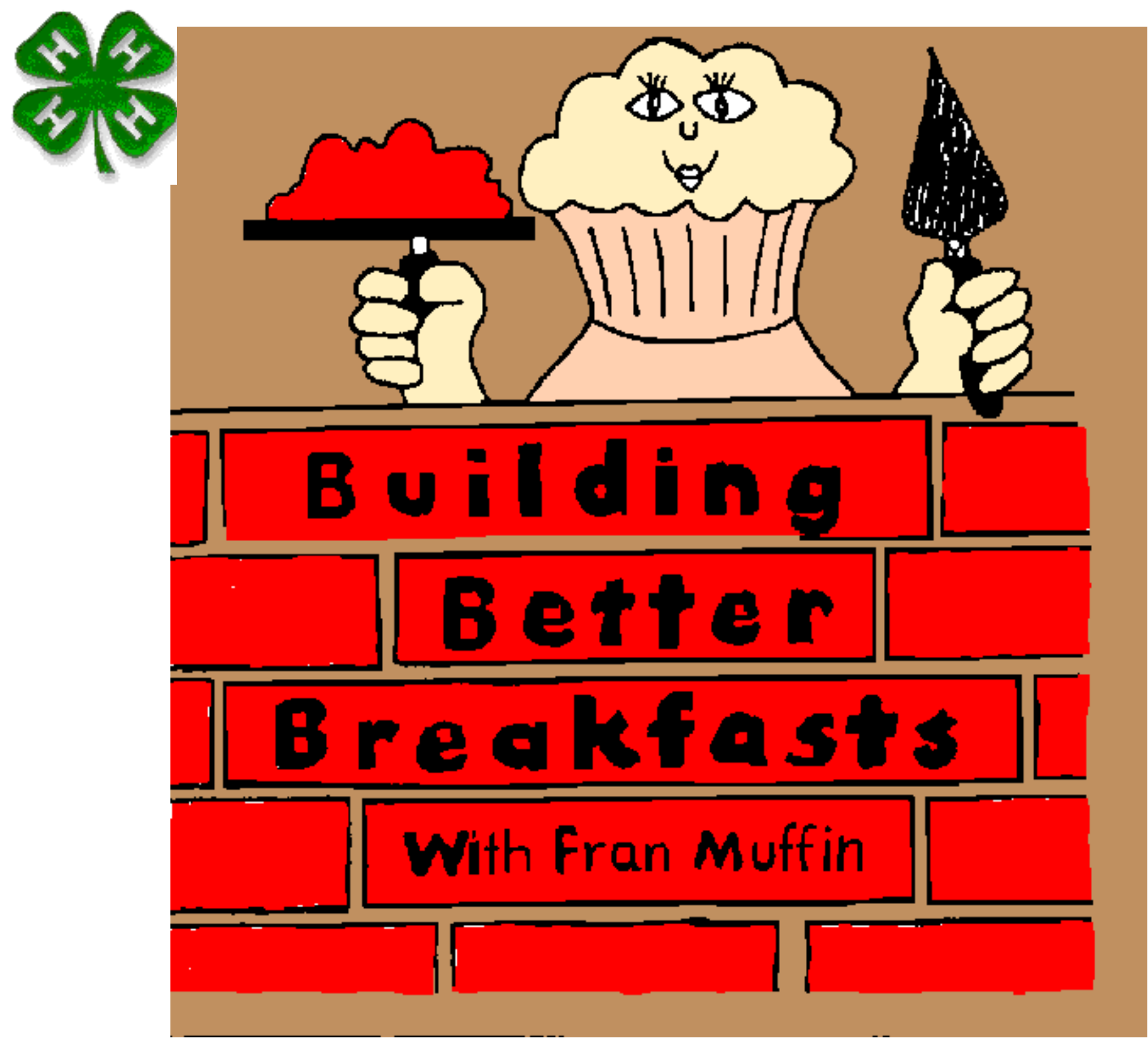
June 30, 1914 Acts of Congress; and is authorized to provide research, educational information and other services only to individuals and institutions that function without regard to race, color, sex, handicap or national origin. Single copies of extension publications (excluding 4-H and youth publications) are available free to Florida residents from county extension offices. Information on bulk rates or copies for out-of-state purchasers is available from C.M. Hinton, Publications Distribution Center, IFAS Building 664, University of Florida, Gainesville, Florida 32611. Before publicizing this publication, editors should contact this address to determine availability. Revised, printed 3/96; reviewed, June 2002. 


\title{
BUILDING BETTER BREAKFASTS
}

\author{
A Nutrition Education Program
}

for 4-H Youth

This education program was developed from a project funded by a grant from the Florida Nutrition Education Training (NET) Program, State of Florida Department of Education, to the University of Florida Home Economics Department. NET funds are provided by the U.S. Department of Agriculture through the Nutrition Education and Training Programs (P.L. 95-166), an amendment to the Child Nutrition Act.

This program is available to all persons regardless of age, color, handicap, national origin, religion, race, or sex. Persons who believe they have been denied equal opportunity for participation may write to: Administrator, Food and Nutrition Service, U.S. Department of Agriculture, 3101 Port Center Drive, Alexandria, Virginia 22302.

\section{Developed by:}

Linda Benjamin Bobroff, Ph.D., RD, LD

Associate Professor

Home Economics Department

Institute of Food and Agricultural Sciences

University of Florida

M. Joy Cantrell, Ed.D.

Associate Professor

Department of 4-H \& Other Youth Programs

Insitute of Food and Agricultural Sciences

University of Florida
Linda L. Christian, B.S.

Graduate Student

Department of Food Science and Human Nutrition Institute of Food and Agricultural Sciences

University of Florida

Carol Frazee, M.S., C.H.E.

Nutrition Education and Training Coordinator

State of Florida Department of Education

\section{Illustrations:}

Ralph Knudsen, Artist

Angela Frampton, Nikki Harvey, Trey Killingsworth, Word Processing \& Graphics

\section{Special thanks to:}

\author{
Barbara Brown, M.S. \\ Mary Hall, M.L.S. \\ Nancy Gal, M.S. \\ Joan Shoeffel, Ph.D.
}




\section{TABLE OF CONTENTS}

\section{INTRODUCTION}

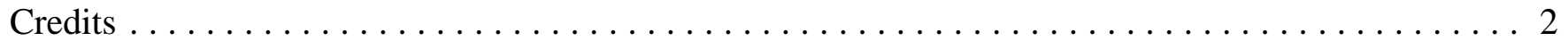

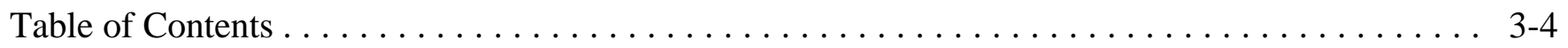

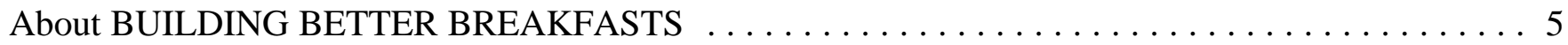

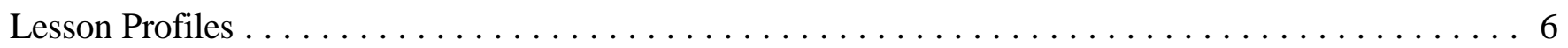

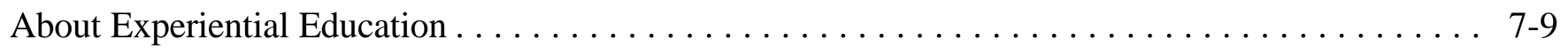

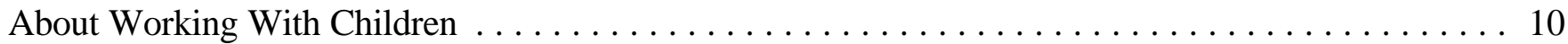

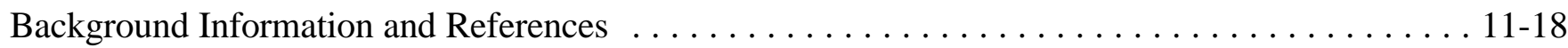

\section{4-H BUILDING BETTER BREAKFASTS}

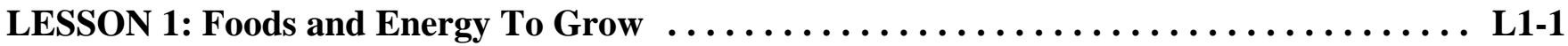

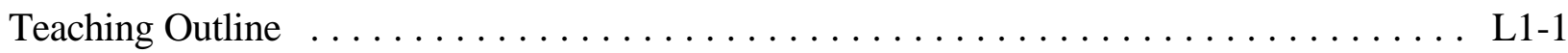

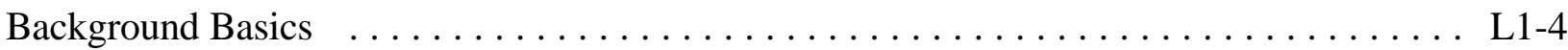

Activities

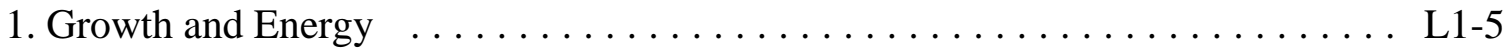

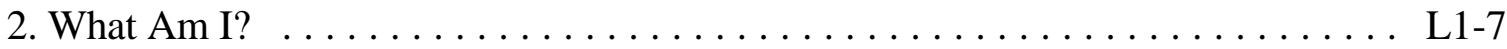

3. A Day Without Breakfast $\ldots \ldots \ldots \ldots \ldots \ldots \ldots \ldots \ldots \ldots \ldots \ldots \ldots \ldots \ldots \ldots \ldots \ldots \ldots, 1-12$

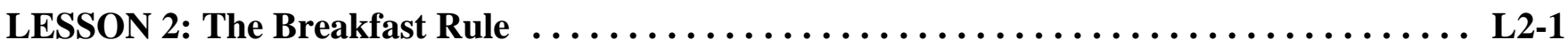

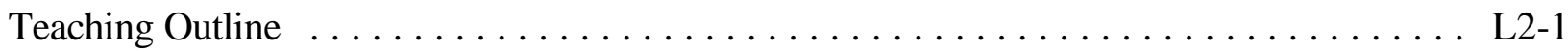

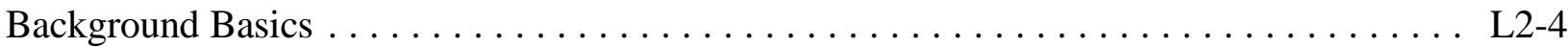

Activities

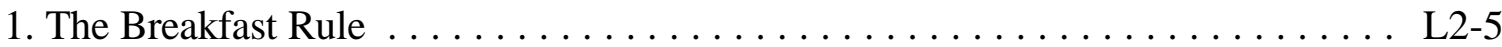

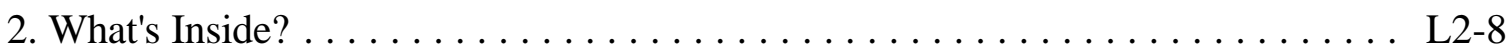

LESSON 3: Cultural Diversity $\ldots \ldots \ldots \ldots \ldots \ldots \ldots \ldots \ldots \ldots \ldots \ldots \ldots \ldots \ldots \ldots \ldots \ldots \ldots$ L3-1

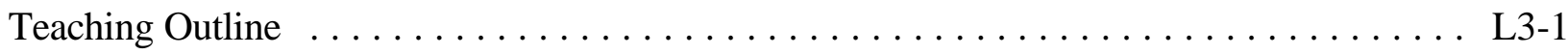

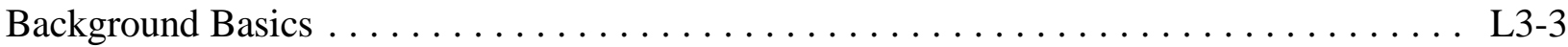

Activities

1. Culturally Diverse Breakfasts $\ldots \ldots \ldots \ldots \ldots \ldots \ldots \ldots \ldots \ldots \ldots \ldots \ldots \ldots \ldots \ldots$

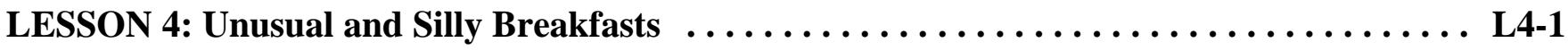

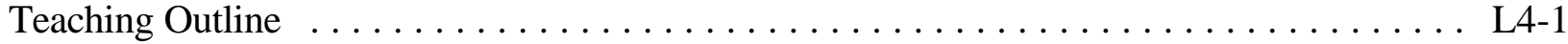

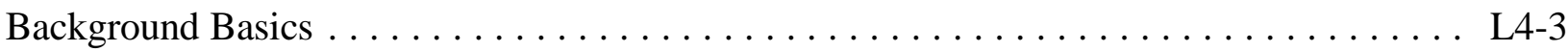

Activities

1. Breakfast Surprises! (Level 1) ....................... L4-4

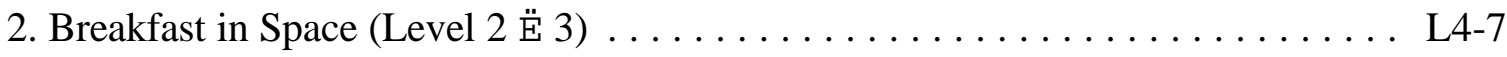

LESSON 5: Build A Breakfast Bread $\ldots \ldots \ldots \ldots \ldots \ldots \ldots \ldots \ldots \ldots \ldots \ldots \ldots \ldots \ldots \ldots$ L5-1

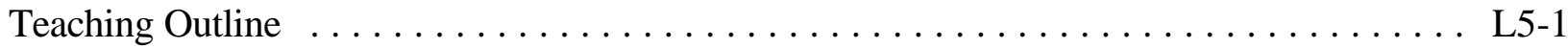

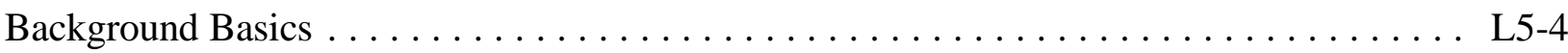

4-H BUILDING BETTER BREAKFASTS $\quad$ Page 3 


\section{TABLE OF CONTENTS (con't)}

Activities

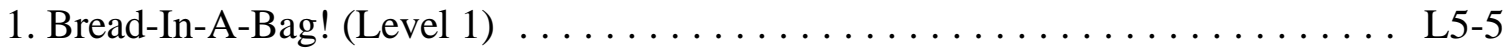

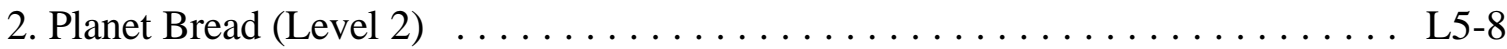

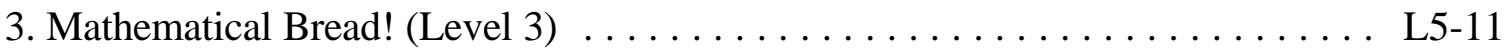

\section{TAKE-HOME}

\section{EVALUATION TOOLS}

Volunteer/Teacher Reporting Forms

Weekly Record Sheet

Fifth grade Quiz

Optional Tools:

Report Card

Breakfast Quiz

\section{RECOGNITION}

Certificate

\section{SUPPLEMENTAL ACTIVITIES}

\section{Loan Kit Order Form}

2. Additional Resources

Videotape 


\section{About....BUILDING BETTER BREAKFASTS}

\section{GOALS}

This unit was developed to inform Extension 4-H agents and home economists, 4-H leaders, and 4-H youth ages 5 to 11 of the importance of eating breakfast, and to give them practical strategies for selecting and/or preparing palatable, culturally acceptable, and nutritious foods for breakfast.

\section{DESCRIPTION}

This unit consists of five lessons that were designed for use with children in kindergarten through fifth grades. Each lesson includes several learning activities, allowing flexibility to 4-H leaders or agents, depending on the attention span and ability of the children, time available for each activity, and facilities available.

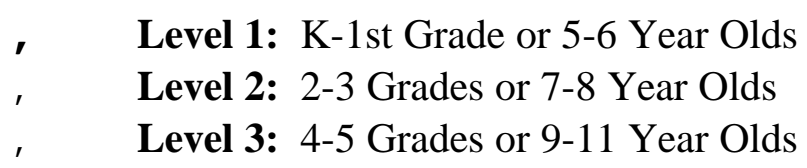

It is left up to the 4-H leader or agent to select the materials most appropriate for their group; the grade levels can be used as a guide, but children's abilities will vary. Some learning activities utilize worksheets which are included in the packet. Each is named and each corresponds to a grade level or levels. Look for Fran Muffin holding a grade sign on each activity sheet and find its name in ALL CAPS in the text.

Supplemental worksheets are also included in the packet. They can be used to supplement the lessons or as stand-alone worksheets at any time. All of the activity sheets are camera-ready and can be reproduced for the 4-H'ers. PLEASE DO NOT USE THE ORIGINALS; THEY NEED TO BE LEFT IN THE PACKET FOR OTHERS TO USE.

\section{TIME}

The duration of the lessons will vary, depending on the number of learning activities included, and how each leader plans the lesson.

\section{EDUCATIONAL RESOURCES}

In addition to the activity sheets developed for this unit, there are additional resources that can be used to supplement the lessons. These are can be found in the Supplemental Activities Section. 


\section{LESSON PROFILES}

A brief description of the five BUILDING BETTER BREAKFASTS Lessons:

\section{! LESSON 1 - FOODS AND ENERGY TO GROW}

Breakfast provides our bodies with "Energy Foods" to start our day. The importance of breakfast and the foods needed daily is the focus of Lesson 1. This lesson provides a foundation for learning about a healthy diet using the food pyramid and the effect of going without breakfast.

\section{! LESSON 2 - THE BREAKFAST RULE}

Variety is the secret to healthy breakfast choices presented as the "Breakfast Rule" in Lesson 2. Choosing at least three of the five food groups is the key to variety. Youth will be introduced to bread as a healthy breakfast choice and learn about its ingredients, setting the stage for a bread baking experience in the last lesson.

\section{! LESSON 3 - CULTURAL DIVERSITY}

Appreciating and respecting others' food preferences is the theme of this lesson. Lesson 3 provides active experiences for children to identify and discover the food preferences of individuals, families and other cultures.

\section{! LESSON 4 - UNUSUAL \& SILLY BREAKFASTS}

Children can discover that any food can be a "breakfast food" in the activities. Tasting unusual breakfast foods provides them with first-hand experiences.

\section{! LESSON 5 - BUILDING A BREAKFAST BREAD}

The skill of making quick breads is the objective of Lesson 5. Youngsters will have the fun opportunity to "build" their breakfast breads with their own ingredient choices. 


\section{BACKGROUND INFORMATION}

The following information will provide you with the research-based information you will need to teach the lessons. Supplemental information and educational materials may be available from your Extension family and consumer sciences educator.

\section{$\underline{\text { Introduction }}$}

Breakfast is important since it is the meal that breaks a 10 to 14 hour fast. If breakfast is not eaten the overnight fast may stretch to 18 hours. For the child who has not had breakfast, the morning's school work may be lost altogether. Common sense says that it is not reasonable to expect a child to learn and work on no fuel, and research studies support this premise (1-5). Breakfast is an important contributor to total nutrient intake in children $(6,7)$.

The first National Evaluation of School Nutrition Programs (NESNP-1) found that 12\% of public school students did not eat breakfast (8). Those most likely to skip breakfast were older and female. Children from homes where the female head of household was employed were less likely to eat breakfast. Finally, African American students were less likely than whites to have breakfast (9).

The purpose of this educational program Building Better Breakfasts is to encourage students to have breakfast everyday. They will learn to identify healthful eating habits and how to prepare simple yet nutritious breakfasts that will give them the energy they need to perform their best each morning.

\section{Consequences of Skipping Breakfast}

Reports in the scientific literature suggest that healthy, normally nourished children cannot do their best work without breakfast (1-5). Already malnourished children may exhibit an even more severe reaction to skipping breakfast (5). Effects may include physical, behavioral, and scholastic consequences.

Physical Consequences. Breakfast supplies our bodies with a variety of nutrients needed for energy, tissue growth and repair, and other bodily functions. Eating breakfast correlates positively with daily intakes of calcium, vitamins $\mathrm{A}, \mathrm{D}, \mathrm{E}$, and $\mathrm{B}_{6}$, and the minerals magnesium and calcium (7). School-age children often have low intakes of these nutrients, especially when breakfast is not eaten (9).

Iron deficiency anemia, a nutritional deficiency affecting nearly 25 percent of poor children in the U.S., is associated with impaired cognitive development (10). Iron is not usually eaten in large amounts at breakfast, although many breads and cereals are fortified or enriched with this mineral, along with thiamin, riboflavin, and niacin. Eggs also contain iron (in the yolk). Iron from plant sources is better absorbed when eaten with acid foods, like orange or grapefruit juice. 
Because of their size, the effects of fasting occur more quickly in children than in adults. Food is needed to maintain blood glucose levels, primarily to supply glucose to the brain. In the absence of food, the liver releases glucose into the blood by breaking down stored glycogen. After glycogen is depleted, protein is converted to yield glucose. The average child up to the age of ten must eat every four to six hours to maintain blood glucose without breaking down body protein, because their livers have only a four to six hour supply of stored glycogen (11). Also, the ratio of a child's brain weight to liver size is larger than that of an adult, and children have a 50 percent greater metabolic rate per unit of brain weight. All of these factors combine to put a great demand on limited liver glycogen stores in children, and make breakfast an especially important meal for them (3). Pollitt et al., suggest that the metabolic effects of fasting described above are associated with behavioral changes that can adversely affect school performance of children who skip breakfast (3).

Behavioral Consequences. Negative classroom behavior may occur when breakfast is skipped. An increase in nervous habits and hyperactivity as well as decreases in attention span, and frustration tolerance have been reported $(12,13)$. Behavior problems and distraction may result from hunger pains themselves $(5,13-15)$, or they may be caused by the release of the catecholamine epinephrine, also known as adrenaline, as a consequence of a decrease in blood glucose levels (3). Blood glucose changes may also affect levels of substrates in the brain that are important in cognitive function (4).

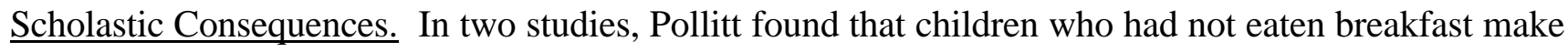
more errors on a test that required them to match familiar figures. Scores on the test were positively correlated with scores on standard education achievement tests $(3,4)$.

Reading and arithmetic skills also suffer in breakfast skippers (13). Children who skip breakfast have been found to have decreased ability to solve continuous task problems on the mornings that they do not eat breakfast (16). These studies were done as crossover studies in which each child was compared to his own performance on fast versus breakfast mornings. Since significant differences in performance were found comparing data from the fast and breakfast mornings, it is apparent that the effects of skipping breakfast are reversible.

All of these findings point to the importance of eating breakfast, especially for school-aged children. But what is a good breakfast?

\section{$\underline{\text { School Breakfast Program }}$}

The School Breakfast Program was established by Congress to assist schools in providing nutritious morning meals to children. The program feeds millions of school children, primarily low-income young people who would otherwise arrive at school hungry (17). As of the 1991-92 school year each school district in Florida was required to implement school breakfast programs in all elementary schools. In 1993, 2,350 schools in Florida offered breakfast, serving (among others) 283,466 low-income students (17). This is significant since low-income children are at greater risk of being hungry and malnourished. Breakfast at school is required to provide one-fourth of the Recommended Dietary Allowances for protein, vitamins, and minerals (18). A complete school breakfast consists of: 
1) $1 / 2$ pint of fluid milk (no substitutions allowed)

2) $1 / 2$ cup serving of a vegetable or fruit, or full-strength vegetable or fruit juice

\section{AND}

3) two servings of either bread/bread alternative or meat/meat alternative OR one serving of bread/bread alternate and one of meat/meat alternate

In Florida, school food authorities are allowed, but not required, to implement "offer versus serve" in their breakfast programs. The difference in schools implementing or not implementing offer versus serve is in what a student is required to take of the offered breakfast. In schools not implementing offer versus serve, a student must take full portions of all four food items offered. In schools implementing offer versus serve, students are allowed to refuse any one food item that they do not intend to eat. The refused item may be any of the four items offered to the student. A student's decision to accept or refuse one of the four food items does not affect the charge for breakfast. "Offer versus serve" may be implemented at all grade levels, or may be restricted to certain grade levels.

In October 1993, USDA reported the results of an assessment of the School Breakfast and School Lunch Programs, which indicated a need to reduce the levels of fat, saturated fat, cholesterol, and sodium in these meals in accordance with the Dietary Guidelines for Americans (19). In the summer of 1994, USDA's Food and Nutrition Service proposed the School Meals Initiative for Healthy Children which would effect major changes in school breakfast and lunch menus to decrease long-term health risks of children. The new nutrition standards also attempt to appeal to children's tastes by providing attractive and tasty food choices that children will accept. The anticipated date of implementation is July 1, 1998.

Since children are not at school everyday, it is important for them to be able to choose a healthful breakfast at home. This is also good training for when they are older and no longer in school. The next section describes what Building Better Breakfasts means when children are eating away from school.

\section{Building Better Breakfasts at Home}

A nutritious breakfast is one that provides adequate energy (calories) along with a variety of other nutrients, like protein, fat, carbohydrates, vitamins, and minerals. Generally, children should be encouraged to eat a meal which includes at least one serving from each of the following groups: Dairy; Fruits or Vegetables; and Grains. Recall that the School Breakfast Program includes two servings from the Grain group (or one each from the Grain and Meat/Meat Alternate groups). This ensures that the meal provides 25 percent of the RDA's for children.

Foods in each food group provide specific nutrients needed by our bodies everyday for fuel, growth and maintenance. Therefore, it is extremely important to eat a variety of foods everyday from these food groups, as well as from the Meats/Meat Alternates group. Within each group there are a variety of foods to choose from, and children should be encouraged to select foods they enjoy. However, 
children also need opportunities to try new foods, and 4-H nutrition lessons can be a positive environment in which they learn to accept different foods.

Examples of the types of foods that can be selected for breakfast from each of three food groups are given below. In the lessons on cultural diversity, the children will learn about different types of foods eaten by ethnic and cultural groups in our state.

\section{Dairy/milk/yogurt}

8 ounces milk or

1.5 ounces cheese or

8 ounces plain yogurt or

5 tablespoons dry milk
Fruits or Vegetables

1/2 cup fruit or

$1 / 2$ cup fruit juice or

$1 / 2$ cup vegetable juice or

$1 / 2$ cup vegetables

\section{Cereal/grains}

1 muffin or $1 / 2$ bagel or

1 slice bread or $3 / 4$ cup hot or 1

oz. cold cereal or

1 tortilla

Caregivers and educators should realize that suggested serving sizes are reasonable amounts to present to a child, but how much a child eats or drinks should depend on his or her own hunger or thirst. Of course, extra helpings can be offered, but it is better for a young child to ask for more than to be overwhelmed with too much on the plate. This may not be a problem with older, active children!

Adding a serving from the meat/meat alternates food group might make the meal cost more, but would increase the contribution the meal makes toward the nutrients needed for that day.

There are some important things to remember about the food groups. First, a cereal-grain food is any that is made from the seeds of a grass. Grasses commonly eaten in the United States include: rye, barley, corn, oats, wheat, and rice. Ethnic foods that may be chosen from this group include tortillas, pastas, rice, and matzos.

Second, although they are dairy products, butter and cream cheese are not included in the dairy food group. This is because they are essentially all fat and do not contain appreciable amounts of important nutrients like calcium and protein that foods in the dairy group provide. Sour cream also is high in fat and is not included in the dairy foods group.

Last, fruit drinks and jams and jellies should not be considered fruit servings because they are usually loaded with sugar *. A serving of fruit should contain mostly fruit with a minimum of added flavors and sugars. Fresh, canned, or dried fruit are all considered fruit servings. Canned fruit in fruit juice or extra light syrup is recommended instead of fruit in heavy syrup. Most children enjoy sweet foods and need not give them up. However, in addition to foods made with sugar, children should be encouraged to enjoy naturally sweet foods like fresh fruits that provide other nutrients as well. We have a wide variety of tropical fruits available in Florida which young people can be encouraged to try. When cost is a factor, fruits should be bought in season when they are the best buy.

* White sugar, brown sugar, raw sugar, honey, sucrose, corn syrup, corn sweetner, glucose, fructose, sorbitol, 
Fat is needed by everyone, especially young children, but many young people eat too much. Fat is found in their diets in the form of hamburgers, hot dogs, chips, ice cream, luncheon meats, and fried foods, etc. These foods can fit into a wholesome diet if consumed in moderate amounts. Most of the time, however, lower fat choices like lean meats instead of hamburger, fresh fruit instead of chips with a sandwich, ice milk or low-fat ice cream instead of regular ice cream, and so on should be consumed by the whole family (except children under two years of age). Children under the age of two need proportionally more fat and cholesterol in their diets than do older children and adults. They should not be a part of a family's low-fat eating plan!

Does the information on fat and sugar mean that foods high in these nutrients are "bad" foods? Not at all. No food is really "bad" if used in moderate amounts. Foods high in fat and/or sugar can play a role in children's diets although it is recommended that they be used sparingly. In short, foods high in sugars and fats can be a part of a healthy diet of most individuals if use is moderate and responsible.

\section{Cultural Eating Patterns}

The idea that any nutritious food is appropriate to eat at breakfast may help children to be able and willing to eat the meal. A slice of left-over pizza is as good as a traditional breakfast of pancakes and sausage. In some ways the pizza may be better. It is certainly faster. This flexibility gives the picky-eater a wider array of foods to choose from for breakfast and, hopefully, increases the chance that s/he will eat something.

Both in the past and present, people of the different cultures of Florida have had diverse traditional breakfast eating patterns. The traditional breakfast foods and meal patterns of some of the major ethnic groups in the state follow to augment the teaching of the Cultural Diversity lesson in this program.

Seminoles. Historically--before the 1920's--these early Floridians raised corn, pumpkin, sweet potato, squash, beans, peas, melons, sugar cane, banana, and sour orange. Some had cassava (a starchy root). They gathered blueberries, huckleberries, wild plums, guavas, honey, and cabbage palm hearts. The Seminoles hunted gopher tortoise, aquatic turtle, quail, curlew (a wading bird), duck, bear, deer, lake bass, trout, garfish, and alligator. Most food was cooked in one pot as stews or gruels called sofki. It was available on the fire at all times of the day and night. There were no set mealtimes. People ate from the sofki pot when they were hungry (20).

Florida Cracker and African American. Grits and biscuits are breakfast staples for these groups. These are served with eggs and red-eye (southern ham) or brindle (bacon fat mixed with flour) gravy. Sweet potato might be incorporated into the biscuits. They might be topped with ham, bacon, sausage, or fried salt pork. Also, corn syrup, molasses, sugar syrups, and honey could accompany the biscuits. Jellies or jams made from persimmons, maypoles, muscadines (native grapes), figs, guava, and orange marmalade might also be used (20).

* White sugar, brown sugar, raw sugar, honey, sucrose, corn syrup, corn sweetner, glucose, fructose, sorbitol, 
Chinese and Oriental. Often members of these groups do not have special breakfast foods. Foods eaten at other meals are also eaten at breakfast. A traditional southern Chinese breakfast might include steamed, fried, or baked meat dumplings and rice gruel flavored with pickled vegetables, bits of meat, legumes, nuts, and seeds. A northern Chinese might have soy milk and fried crullers dipped in sugar eaten with pickled or stir fried dishes (20).

Cuban. For breakfast Cubans may eat pan con mantequilla (bread and butter) and cafe con leche (3/4 milk and 1/4 sweetened coffee)--even the children. Also, fruit juices might be mixed with milk for another breakfast drink. Fruit such as grapefruit, limes, oranges, mangoes, guavas, mamay, papayas, coconut, or banana may be eaten (20).

Mexican. In rural areas the people from this southern neighbor eat a small breakfast around 5:00 a.m. of sweet breads and cafe con leche or hot cocoa. A larger second breakfast of tortilla and beans and chili sauce would then be eaten around 9:00 a.m. (20).

\section{$\underline{\text { Conclusion }}$}

Breakfast is a vital part of morning preparation for the day. It is the fuel needed to help children function at their best in the early part of the day. Children should be encouraged to eat breakfast everyday so that they can get the most out of their morning at school or at home.

IMPORTANT NOTE -- To avoid foodborne illness, please remember when planning activities that involve food, all perishables must be kept refrigerated. Perishable foods should not be left at room temperature for more than two hours, even less if the temperature is very warm. Also be sure that the children wash their hands with soap before handling food. 